\title{
Path Research of Developing Nighttime Cultural Tourism under the Condition of Prominent Limiting Factors A Case Study of Hohhot
}

\author{
Wenwen Bao, Yaolu Ma, Wenjing Fan* \\ Beijing Institute of Graphic Communication, Beijing, China \\ "Corresponding author. Email: fanjiaruo@126.com
}

\begin{abstract}
Nighttime cultural tourism has become a trend in China, however, there are indeed prominent limiting factors to develop it for some cities, especially in the case of Hohhot. This study adopts an empirical research method and finds low temperature at night especially in winter, unfamiliar region for people and relative low consumption level of residents are prominent limiting factors of Hohhot's nighttime cultural tourism development. It shows that limiting factors are not determinants to develop nighttime cultural tourism in Hohhot, which is based on theoretical tools about cultural industry and tourism. In fact, Hohhot has much potential to develop the nighttime cultural tourism through circumvention of outdoor activities in low temperature's days, making people aware of favorable conditions of traffic and making full sense of local consumers. Meanwhile, this study is to provide ideas of developing nighttime cultural tourism to cities existing general problems as Hohhot.
\end{abstract}

Keywords: Nighttime cultural tourism, Path research, Hohhot.

\section{PRESENT SITUATION OF HOHHOT NIGHTTIME CULTURAL TOURISM DEVELOPMENT}

It is incipient stage of Nighttime Cultural Tourism development in Hohhot. In May 2020, Hohhot issued the Guiding Opinions on Promoting the Development of Nighttime Economy in Hohhot City. It involves planning about building a well-known domestic Night Qing Cheng, which means night Hohhot consumer brand. It also plans to build foundation of nighttime cultural tourism in Hohhot in three years. At the present, there are three main types about projects of nighttime cultural tourism in Hohhot, including going to the internet-famous sites, consuming in the food commercial pedestrian streets, and doing sports at night. It is not frequent for people to participate in characteristic intangible cultural heritage activities or attend cultural and entertainment performances.

\section{BRIEF DESCRIPTION OF PROMINENT LIMITING FACTORS OF NIGHTTIME CULTURAL TOURISM DEVELOMENT IN HOHHOT}

\subsection{Climate Makes Demands Unstable of Nighttime Cultural Tourism in Hohhot}

Hohhot is located in the central part of Inner Mongolia Autonomous Region. It has a typical temperate continental climate, which makes places' winter long and cold, dry and windy in Spring. Besides, it has large temperature differences both in day and night as well as seasons. For nighttime cultural tourism requiring high standards of temperature conditions, the influence is prominent, thus, it leads to the instability of demands about nighttime cultural tourism in Hohhot. 


\subsection{Region's Unfamiliarity Affects Demands Completeness of Nighttime Cultural Tourism in Hohhot}

At the present, Hohhot is less familiar to people compared with other cities with a relatively high level of development, especially compared with typical cities for nighttime cultural tourism, such as Xi'an, Shanghai and so on. In fact, Hohhot has developed fast for past years, it is pivotal to find ways to break the stereotypes from people so as to acquire demands completeness and promote local nighttime cultural tourism market through opening.

\subsection{Residents' Consumption Level Bring Uncertainty of Developing Nighttime Cultural Tourism in Hohhot}

As the epidemic hits the economy, there are more unsure factors emerging to affect local residents' consumption level. This kind of uncertainty weakens consumer's willingness of nighttime cultural tourism in a way. At the foundation of insufficient consumer stickiness to relative market before, it is inadequate to say that nighttime cultural tourism market in Hohhot can be established depends on consumers totally.

\section{CIRCUMVENTION TO PROMINENT FACTORS AND DISCUSSION OF POTENTIAL ADVANTAGES}

According to present situation of Hohhot nighttime cultural tourism development and prominent limiting factors of it, the paper tries to discuss ways of circumvention to prominent factors and to show potential advantages of developing nighttime cultural tourism in Hohhot, which is based on theoretical tools about cultural industry and tourism.

\subsection{Continuous Improvement Transportation System Enhances Superiority of Hohhot's Position as One of the Tourism Destinations}

In recent years, Hohhot has made a qualitative leap in the construction of its airport, high-speed rail, subway and road loops. Therefore, as the capital of Inner Mongolia Autonomous Region and the center of politics, economy, culture, science, education and finance, Hohhot has more chances to contact with cities via transportation superiority, which have higher economic levels, such as Beijing, Tianjin, etc. The improvement of the transportation system has made Hohhot more advantageous as a region for nighttime cultural tourism.

\subsection{Having Rich Cultural Resources and $A$ Certain Foundation of Nighttime Cultural Tourism Market}

The nighttime cultural tourism of the city must rely on rich and unique cultural resources. Hohhot, as a city of ethnic minorities, has a large number of extremely attractive cultural and tourism resources. At the same time, as described in the section of present situation of Hohhot nighttime cultural tourism development, it exactly has appropriate quantity of competent cultural and related firms to integrate kinds of cultural resources to nighttime cultural tourism market in Hohhot.

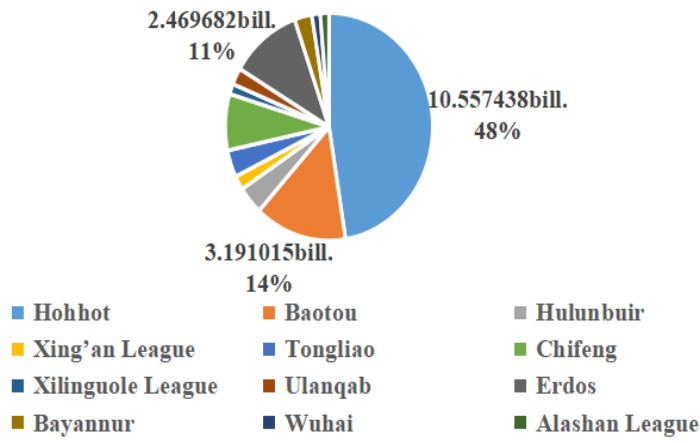

Figure 1 The percentage of business income of cultural and related enterprises in each region of Inner Mongolia.

\subsection{The Government Has Been Giving Supports to Develop Nighttime Cultural Tourism So As to Better Guarantee Consumers' Activities}

The nighttime cultural tourism market has a promising future as the COVID-19 is suppressed and consumers have more possible willingness to spend on tourism in China. At this point, Hohhot has issued several documents related to the promotion and development of Hohhot's economy, aiming to actively promote the recovery of the tourism economy, especially for nighttime cultural tourism. Meanwhile, it takes the opportunities to promote the creation of new special nighttime cultural tourism products and provides preferential consumption, then better guarantee consumers' activities.

\section{POTENTIAL DEVELOPING PATHS AND COPING STYLES OF NIGHTTIME CULTURAL TOURISM IN HOHHOT}

At the foundation of circumvention to prominent factors and discussion of potential advantages, the paper tries to explore paths to develop nighttime cultural tourism in Hohhot by innovative thinking and creative design. 


\subsection{Take Advantage of Nature and Develop STARGAZING ECONOMY Brand}

Due to the geographical and climatic characteristics, Hohhot is located in the plain and dry with little rain, both the city center and the surrounding grasslands are excellent areas for stargazing, which is extremely rare. Therefore, with the natural advantage, the Stargazing Economy could become an unique brand representing Hohhot's and even the Inner Mongolia Autonomous Region's nighttime cultural tourism.

\subsection{Promote Nadam's Popularization and Increase Its Indoor Activities at Night}

To integrate Nadam into nighttime cultural tourism in Hohhot is a comprehensive reflection of significance

Table 1. Basic information of enterprises in cultural and related industries (Based on data from Inner Mongolia Economic Census Yearbook 2018 3-A-05)

\begin{tabular}{|c|c|c|c|c|}
\hline Regions & $\begin{array}{l}\text { Number of legal entities } \\
\text { (Individual) }\end{array}$ & $\begin{array}{l}\text { Number of employees } \\
\text { at the end of the } \\
\text { period (Person) }\end{array}$ & $\begin{array}{l}\text { Total Assets } \\
\text { (Ten thousand yuan) }\end{array}$ & $\begin{array}{l}\text { Operating income } \\
\text { (Ten thousand yuan) }\end{array}$ \\
\hline Total & 19131 & 87621 & 11663978.8 & 222475.11 \\
\hline Hohhot & 3891 & 26097 & 2629539.9 & 1055743.8 \\
\hline Baotou & 2822 & 13048 & 1300416.4 & 319101.5 \\
\hline Hulunbuir & 1752 & 5979 & 459118 & 88965.4 \\
\hline Xing'an League & 587 & 2705 & 232890.2 & 44667.4 \\
\hline Tongliao & 1513 & 5522 & 1187797.5 & 85674.1 \\
\hline Chifeng & 2644 & 10562 & 1251860.6 & 178421.6 \\
\hline Xilinguole League & 834 & 3329 & 192714.7 & 32554.6 \\
\hline Ulanqab & 1025 & 4202 & 337118.9 & 52964.3 \\
\hline Erdos & 2381 & 9954 & 3047150.2 & 246968.2 \\
\hline Bayannur & 800 & 2976 & 181562.5 & 60466.9 \\
\hline Wuhai & 581 & 1842 & 184988.3 & 29129.8 \\
\hline Alashan League & 301 & 1405 & 658821.6 & 30097.5 \\
\hline
\end{tabular}

\subsection{Combine Nighttime Cultural Activities with More Cultural Tourism Festivals and Construct Flexible Hosting Model of Nighttime Cultural Tourism in Hohhot}

The development of nighttime cultural tourism requires a large amount of capital and manpower investments, in order to alleviate the pressure of all parties, especially for the most related firms with small volumes, Hohhot can combine nighttime cultural activities with more flexible forms. Under this premise, relying on various cultural tourism festivals, such as Zhaojun Cultural Festival, China, Russia and Mongolia Tourism Festival, etc. to promote Limited Time consumption of nighttime cultural tourism maybe a direct way to construct the unique hosting model of about cultural resources, region characteristics and people's demands in hearts. In order to better resolve the problems about limiting factors, for example, it is impossible for people to host Nadam all the time and all the places. It is a must to transform Nadam to get more popularization, separating activities according to the standards of indoor activities and nighttime activities. On this basis, permuting and combining indoor nighttime activities of Nadam in different ways to cope with the limiting factors about temperature and time. From this, Hohhot nighttime cultural tourism will become more national and diversiform. 
their income's allocations. For Hohhot tourists, especially local residents, they may not have much income compared to higher economic cities, but they are willing to pay for nighttime cultural tourism as well. From this way, it is necessary to make full sense of them. At the last but not least, presenting own favorable conditions of nighttime cultural tourism in Hohhot sufficiently to all kinds of tourists has become one of the most important things currently.

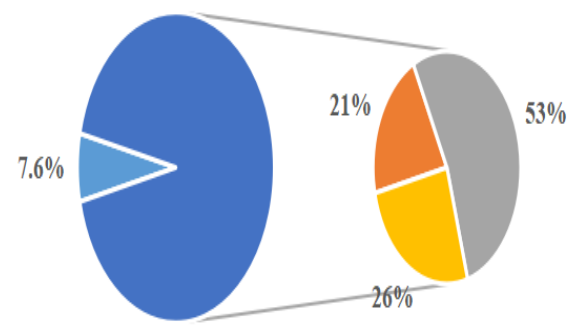

- Tourists who have no nighttime cultural tourism experience

- Tourists who would like to experience nighttime cultural tourism once

- Tourists who would like to experience nighttime cultural tourism twice

- Tourists who would like to experience nighttime cultural tourism three times

Figure 2 Demand forecast for nighttime cultural tourism market in Hohhot.

\section{CONCLUSION}

There are no decisive prominent limiting factors but coping styles that adapt to local conditions in Hohhot to develop its nighttime cultural tourism.

\section{AUTHORS' CONTRIBUTIONS}

Wenwen Bao, contributed to the conception of the study, main writing of the manuscript and performance of the data analysis;

Yaolu Ma, contributed to the preparation of manuscript, partial writing of the manuscript and performance of the figures;

Wenjing Fan, helped perform the analysis with constructive discussions.

\section{ACKNOWLEDGMENTS}

Scientific Research Project of Beijing Municipal Education Commission: Research on the Promotion Path of Night Cultural Tourism in Beijing (SM202010015003)

\section{REFERENCES}

[1] Ao Deng. SWOT analysis of Hohhot tourism [J], in: Science and Technology Information, 2009(25):103.
[2] Interpretation of the Tourism Development Plan of the Thirteenth Five-Year Plan of Inner Mongolia Autonomous Region[N/OL], in: Inner Mongolia Fengzhen City People's Government Information Center, 2017 [20].Center, 2017 [2021-04-21].

[3] Policy interpretation of the guiding opinions on promoting the development of nighttime economy in Hohhot [N/OL], in: Hohhot Municipal People's Government, 2020 [2021-04-21].

[4] Nighttime tourism market data report [J], in: China Tourism Research Institute, 2019.

[5] Climate background analysis of Hohhot [N/OL], in: China Climate Network, [2021-4-21]. http://www.weather.com.cn/cityintro/101080101.s html

[6] Inner Mongolia Autonomous Region Statistical Bulletin on National Economic and Social Development in 2020 [M/OL], in: Inner Mongolia Autonomous Region Statistics Office, 2021-2-28 [2021-04-21]. http://tj.nmg.gov.cn/tjgb/21044.html

[7] Inner Mongolia Economic Census Yearbook 2018 [M/OL], in: Inner Mongolia Autonomous Region Statistics Office, [2021-04-21]. http://tj.nmg.gov.cn/Files/2018/zk/indexch.htm

[8] In 2020, Hohhot has these new traffic changes! [N/OL], in: Hohhot News Network, 2020-12-28 [2021-04-21]. http://m.thepaper.cn/baijiahao_10568610

[9] Guiding Opinions on Promoting the Development of Nighttime Economy in Hohhot City [M/OL], in: Hohhot Municipal Government Office, 2020-05-22 [2021-04-21]. http://www.huhhot.gov.cn/zwgk/zfxxgkzl/zfxxgkm 1x/202006/t20200604_684108.html 